\title{
Mapping Texture Phase Diagram of Artificial Haptic Stimuli Generated by Vibrotactile Actuators
}

\author{
Anak Agung Gede Dharma ${ }^{1}$ and Kiyoshi Tomimatsu ${ }^{2}$ \\ ${ }^{1}$ Kyushu University, Graduate School of Design, Fukuoka, Japan \\ dharma@kyudai.jp \\ ${ }^{2}$ Kyushu University, Faculty of Design, Fukuoka, Japan \\ tomimatu@design.kyushu-u.ac.jp
}

\begin{abstract}
We propose a classification method of tactile sensations elicited by artificial haptic stimuli by using Japanese onomatopoeias/adjectives. This method classifies adjectives based on user subjective perception and plot basic components of artificial haptic stimuli. The comparison of perceived tactile sensations from artificial haptic stimuli and genuine physical materials is also discussed in this paper.
\end{abstract}

Keywords: Touch perception, artificial haptic stimuli, Japanese onomatopoeia, Principal Component Analysis.

\section{Introduction}

In this age of media and telecommunication, haptic feedback plays an indispensable role. Haptic feedback is often used simultaneously with visual or audio feedback. However, when separately used, it still has a capability to convey non-intrusive messages. Notable examples of its importance can be found in various devices, such as mobile phone, Personal Digital Assistant (PDA), game controllers, and medical instruments. Furthermore, haptic feedback also plays a significant role for supporting daily lives of visually impaired persons.

On the other hand, haptic feedback design still has remaining problems. Even in this age of media and telecommunication, it is still limited to a combination of simple force patterns. The study about haptic perception is still limited, especially the study regarding sensations elicited by artificial haptic stimuli.

This study proposes a classification method for explaining tactile sensation generated by artificial haptic stimuli. In this study, we evaluate 100 randomly generated artificial vibrotactile stimuli with subjective evaluation method (Semantic Differential Test) and develop a texture phase diagram using the result from Principle Component Analysis. In the sixth section, detailed analysis of the texture phase diagram and its comparison with preceding researches will also be discussed. 


\section{Related Works}

The attempts of interpreting the correlations between haptic perceptions and physical properties of materials have been discussed in previous studies. Chen et al. [1] and Shirado et al. [2] suggested correlation model to explain the relationships between touch perception and surface physical properties. Shirado et al. [3] proposed a modeling of tactile texture recognition mechanism using human subjective evaluation and computer simulation based recognition model. Furthermore, Hollins et al. [4] and Tiest et al. [5] utilizes Multi Dimensional Scaling to analyze and explain haptic perceptions.

A method to classify tactile textures by using Japanese onomatopoeia has been proposed by Hayakawa et al. [6]. They used 42 Japanese onomatopoeias and Semantic Differential Test to develop a distribution diagram that can explain the correlation between tactile perception and physical characteristics of materials.

\section{$3 \quad$ Research Objective}

The main objective of this study is to explore the correlation model of tactile perceptions that are induced by artificial vibrotactile stimuli. The correlation model can be used to determine cumulative effect that artificial vibrotactile stimuli contribute towards overall tactile perception and relative importance of each extracted components. The cumulative effect can determine whether artificial vibrotactile can be used as an adequate replacement of genuine physical materials or not.

\section{$4 \quad$ Experiment Method}

\subsection{Participants}

Fourteen subjects ( 7 males and 7 females; mean and standard deviation of age were 21.4 and 1.4, respectively) participated in the experiment. All subjects are native speakers of Japanese.

\subsection{Stimuli}

\section{Selective Stimulation Method}

The theory behind selective stimulation method is that tactile receptors in the human skin cannot sense physical factors directly. They can only detect inner skin deformation caused by contact with objects [7]. Therefore, we may be able to use artificial tactile stimulation to activate tactile receptors' nerves as if they were being activated by physical properties of tangible material.

The selective stimulation method is based on the direct manipulation of three tactile receptors: Fast Adapting Afferents Type I (FA1), Fast Adapting Afferents Type II (FA2), and Slow Adapting Afferents Type I (SA1). Each receptor has spatial and temporal response characteristics for physical stimulation, as described in Figure 1. Each receptor also causes subjective sensation that corresponds to inner skin deformation. 
In this study, we stimulate three tactile receptors based on detection thresholds as described by Konyo et al. [7], i.e.: FA1: most sensitive between 25-40 Hz; FA2: most sensitive between 200-250 Hz; and SA1: most sensitive at approximately less than 5 Hz. The detection threshold for each tactile receptor is illustrated in Figure 1.

\section{Stimuli Design}

Our vibrotactile stimuli design concept and the correlation between its variables are illustrated in Figure 2-a. Each stimulus was designed by the superposition of three haptic vibrations of different frequency ranges, i.e. the constructive interference of three different frequency ranges. Six variables for the stimuli design are described in Table 1 .

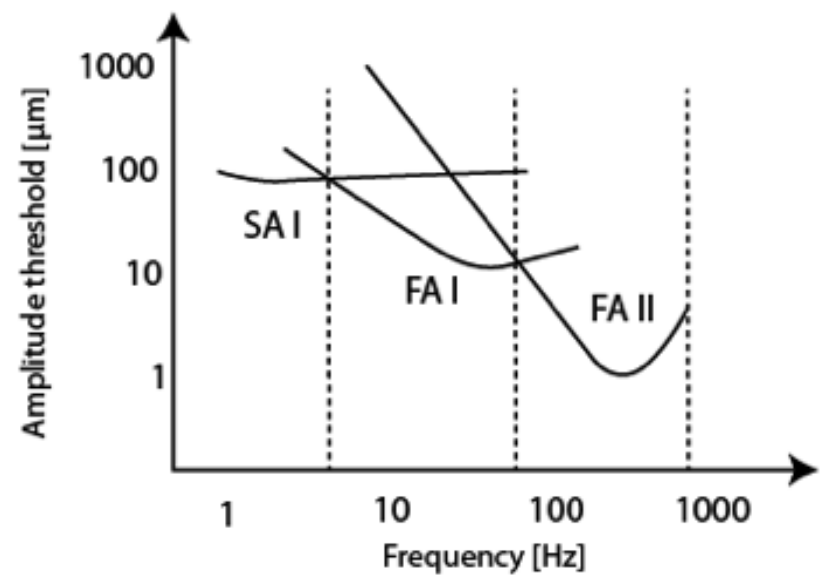

Fig. 1. Detection thresholds of vibratory stimuli based on Konyo et al. [7] that was originally based on Bolanowski et al. [8]

Table 1. Amplitude and frequency variables for a given force pattern

\begin{tabular}{|l|l|l||l|l|l|}
\hline $\begin{array}{l}\text { Amplitude } \\
\text { Variables }\end{array}$ & $\begin{array}{l}\text { Receptor } \\
\text { Target }\end{array}$ & $\begin{array}{l}\text { Amplitude } \\
\text { Range }\end{array}$ & $\begin{array}{l}\text { Frequency } \\
\text { Variables }\end{array}$ & $\begin{array}{l}\text { Receptor } \\
\text { Target }\end{array}$ & $\begin{array}{l}\text { Frequency } \\
\text { Range }(\text { Hz) }\end{array}$ \\
\hline $\begin{array}{l}\text { Amplitude_ } \\
\text { FA1 }\end{array}$ & $\begin{array}{l}\text { FA1 } \\
\text { (Meissner) }\end{array}$ & $0-45$ & $\begin{array}{l}\text { Frequency } \\
\text { FA1 }\end{array}$ & $\begin{array}{l}\text { FA1 } \\
\text { (Meissner) }\end{array}$ & $25-40$ \\
\hline $\begin{array}{l}\text { Amplitude_- } \\
\text { FA2 }\end{array}$ & $\begin{array}{l}\text { FA2 } \\
\text { (Pacinian) }\end{array}$ & $0-12$ & $\begin{array}{l}\text { Frequency } \\
\text { FA2 }\end{array}$ & $\begin{array}{l}\text { FA2 } \\
\text { (Pacinian) })\end{array}$ & $200-250$ \\
\hline $\begin{array}{l}\text { Amplitude_- } \\
\text { SA1 }\end{array}$ & $\begin{array}{l}\text { SA1 } \\
\text { (Merkel) }\end{array}$ & $0-60$ & $\begin{array}{l}\text { Frequency } \\
\text { SA1 }\end{array}$ & $\begin{array}{l}\text { SA1 } \\
\text { (Merkel) }\end{array}$ & $0.4-7$ \\
\hline
\end{tabular}




\section{Stimuli Playback}

100 stimuli were generated in this experiment and evaluated by our subject participants by Semantic Differential (SD) test. The values for six variables of haptic stimulus, as described in Table 1 were chosen randomly. There were no stimuli with identical combination of those six variables. In this experiment, vibrotactile stimuli were displayed using vibrotactile actuators (Figure 2-b).

\subsection{Onomatopoeias}

Japanese onomatopoeias were used for subjective evaluation test (Semantic Differential Test). This study adopts 42 onomatopoeias from Hayakawa et al. [6] and Japanese Onomatopoeia Dictionary [9]. After preliminary testing, 17 onomatopoeias were selected for Semantic Differential Test and constructing Principal Component Analysis (PCA) Diagram. List of onomatopoeias and its English equivalent is described in Table 2 [10]. However, the English equivalent in Table 2 may have different meaning, which depends on its context.

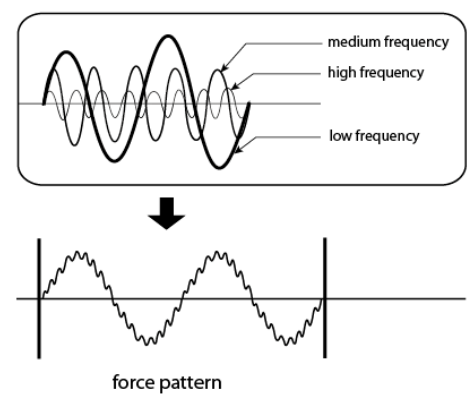

(a)

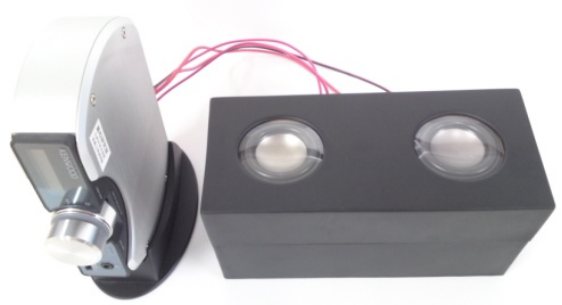

(b)

Fig. 2. (a) Stimuli design by superposition in this research (b) A prototype to display vibrotactile stimuli that consist of a pair of vibrotactile actuators and digital amplifier

\subsection{Procedure}

The experiment was conducted in a room with minimum noise and controlled temperature. The stimuli were generated by vibrotactile actuators as described in Figure 2-b. The stimuli were continuously played while the subject giving scores to Semantic Differential (SD) test. In this study, we used 7-point Likert scale SD questionnaire, both end of bipolar scale consists of "strongly felt" and "not felt at all." There were 17 onomatopoeias and 100 stimuli for SD test, therefore we had 1700 set of data from each participant.

The experiment was held in an hour time limit, i.e. each participant was constrained not to answering more than one hour in a day. If participant couldn't finish all 100 stimuli within one hour, the experiment was rescheduled on a latter day. 
This experiment took approximately a month to finish. All of the data extracted in this experiment were analyzed using R statistics [11].

Table 2. List of onomatopoeias for subjective evaluation questionnaire

\begin{tabular}{|l|l||l|l|}
\hline $\begin{array}{l}\text { Onomatopoeia } \\
\text { (in Japanese) }\end{array}$ & English Equivalent & $\begin{array}{l}\text { Onomatopoeia } \\
\text { (in Japanese) }\end{array}$ & English Equivalent \\
\cline { 2 - 4 } Kasakasa & $\begin{array}{l}\text { A coarse, dried out } \\
\text { feeling }\end{array}$ & Nurunuru & $\begin{array}{l}\text { Greasing, soaping, } \\
\text { making slippery }\end{array}$ \\
\hline Gasagasa & $\begin{array}{l}\text { A coarse, dried out } \\
\text { feeling, coarser than } \\
\text { kasakasa }\end{array}$ & Nechanecha & $\begin{array}{l}\text { Adhesive, like glue, } \\
\text { viscous, greasy }\end{array}$ \\
\hline Kunyakunya & Soft, flexible, supple & Nechonecho & Slimy* \\
\hline Gunyagunya & Soft, disfigured & Korikori & Scraping, crunchy \\
\hline Gorigori & $\begin{array}{l}\text { Hard, having a hard } \\
\text { core }\end{array}$ & Jyarijyari & Sandy, gritty \\
\hline Sarasara & Smooth, light, dry & Jyorijyori & Bristly* \\
\hline Subesube & Smooth, slippery & Kochikochi & Sore and stiff \\
\hline Tsurutsuru & $\begin{array}{l}\text { Smooth, slippery } \\
\text { (stronger than sub- } \\
\text { esube) }\end{array}$ & Nyurunyuru & Squirm, slip away \\
\hline Numenume & Smooth, slimy & & \\
\hline
\end{tabular}

*) The English equivalent could not be found in the reference and a Japanese native speaker were asked to describe the meaning

\section{$5 \quad$ Results}

The result of Principal Component Analysis (PCA) of 17 adjectives is described in Table 3 and its visualization is depicted in Figure 3. In this study, 3 principal components extracted cumulative explained variance of $56.52 \%$, which means that the current model can explain $56.52 \%$ of the overall touch perception.

The first principal component (PC1, 27.17\% of variance) has positive correlation with "nurunuru" and "numenume"; Second principal component (PC2, 19.27\% of variance) positively correlate with "sarasara" and "subesube," and negatively correlate with "jyarijyari" and "jyorijyori"; Third principal component (PC3, 10.07\% of variance) positively correlate with "kochikochi" and "korikori," and negatively correlate to "kunyakunya" and "gunyagunya."

Two-dimensional plotting of PC1 \& PC2, and PC2 \& PC3 are depicted in Figure 3-a and Figure 3-b, respectively. 
Table 3. Component loadings for 17 onomatopoeias for 3 Principal Components

\begin{tabular}{|l|c|c|c||l|c|c|c|}
\hline Onomatopoeia & PC1 & PC2 & PC3 & Onomatopoeia & PC1 & PC2 & PC3 \\
\hline Kasakasa & -0.19 & -0.10 & 0.07 & Nurunuru & 0.38 & -0.05 & 0.01 \\
\hline Gasagasa & -0.18 & -0.33 & 0.03 & Nechanecha & 0.33 & -0.17 & -0.03 \\
\hline Kunyakunya & 0.26 & -0.15 & -0.30 & Nechonecho & 0.33 & -0.17 & -0.02 \\
\hline Gunyagunya & 0.26 & -0.19 & -0.28 & Korikori & 0.13 & -0.25 & 0.32 \\
\hline Gorigori & 0.02 & -0.32 & 0.19 & Jyarijyari & -0.13 & -0.37 & 0.22 \\
\hline Sarasara & 0.10 & 0.35 & 0.32 & Jyorijyori & -0.11 & -0.35 & 0.27 \\
\hline Subesube & 0.21 & 0.32 & 0.36 & Kochikochi & 0.05 & -0.19 & 0.45 \\
\hline Tsurutsuru & 0.25 & 0.24 & 0.35 & Nyurunyuru & 0.36 & -0.07 & -0.07 \\
\hline Numenume & 0.37 & -0.08 & 0.01 & & & & \\
\hline
\end{tabular}

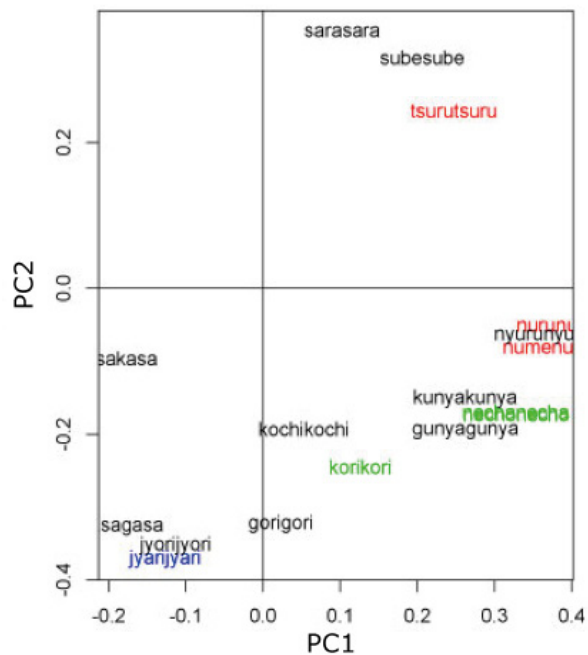

(a)

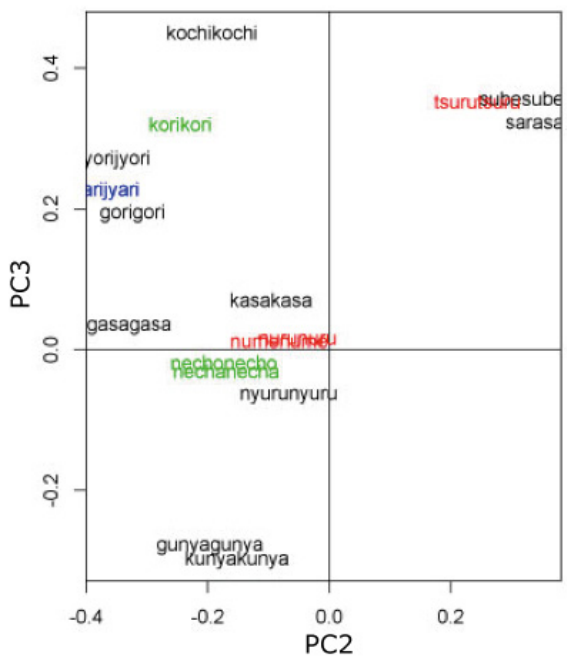

(b)

Fig. 3. Texture phase diagram of 17 onomatopoeias based on Principle Component Analysis

\section{Discussion}

\subsection{Analysis of Texture Phase Diagram}

Each principal component can be renamed according to the adjectives that have strong correlation with it. Another matter that needs to be considered is the 
comparison to preceding researches by Hayakawa et al. [6] and Hollins et al. [4]. Our experiment result suggests that the adjectives that correlate with PC1, PC2, and PC3 represents moisture, friction, and hardness, respectively. This finding is in accordance with Hayakawa et al. (friction, hardness, and moisture) and similar with Hollins et al. who propose softness-hardness and roughness-smoothness as two of the most important element in tactile sensation.

The plotting of 3 basic components of artificial vibrotactile stimuli, i.e.: FA1 ( 30 $\mathrm{Hz})$, FA2 $(\sim 225 \mathrm{~Hz})$, and SA1 $(\sim 5 \mathrm{~Hz})$ are described in Figure 4. This plotting is approximate and based on average score of each adjective. FA1 corresponds to "jyarijyari," "jyorijyori," and "gasagasa"; FA2 corresponds to "gasagasa" and "kasakasa"; and SA1 corresponds to "kunyakunya" and "gunyagunya."

The superposition of more than one basic component (FA1, FA2, or SA1) results in a combined properties from both components in the new stimulus. For example, combining SA1 and FA1 will result in vibrotactile stimuli that correlate with "kunyakunya," "gunyagunya," "jyarijyari," "jyorijyori," and "gasagasa." Furthermore, the non-existence of a basic component (FA1, FA2, or SA1) will cause a haptic stimulus to be located on the opposite polar of its counterpart. For example, stimulus with very low Amplitude_FA1 is located nearby "sarasara," "subesube," and "tsurutsuru."

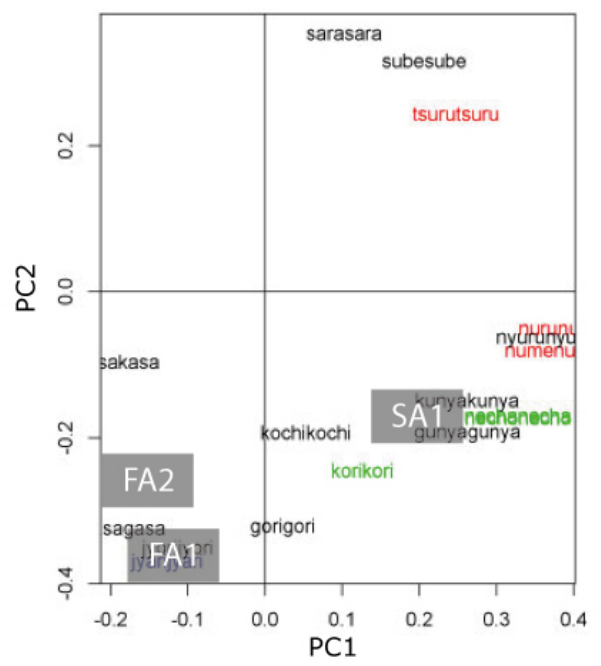

(a)

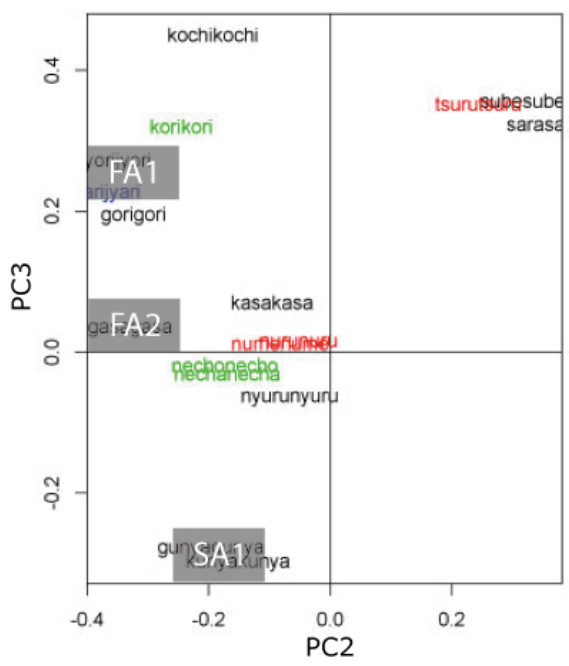

(b)

Fig. 4. Texture phase diagram of 17 onomatopoeias based on Principle Component Analysis and artificial stimuli plot 


\subsection{Comparison between Texture Phase Diagram of Physical Materials and Artificial Stimuli}

This study gives similar result to previous studies in texture phase mapping, as described in section 6.1. However, there are some differences that are discovered in this study. Although our experiments yield the same principal components as Hayakawa et al., we found that the order of principal components is different. In texture phase diagram of physical materials by Hayakawa et al., the order of principle components are friction, hardness, and moisture, as measured by the number of variance explained. However, we found that dampness ( $\mathrm{PC} 1,27.17 \%$ of variance) is the principle component that explains most of the variance, followed by friction (PC2, 19.27\% of variance) and hardness (PC3, 10.07\% of variance). We argue that vibrotactile actuators cannot adequately generate hardness sensations and more suitable to be used for generating friction or moisture sensations. Directly stimulating Meissner or Pacinian corpuscle by vibrotactile actuators can emulate those sensations.

\section{Conclusion and Future Works}

This study has proposed a new classification method of tactile sensations generated by artificial vibrotactile stimuli. A texture phase diagram has been developed that can be used to explain the correlation between artificial vibrotactile stimuli and tactile perception. In addition, the comparison to tactile sensations generated by physical materials has also been discussed.

Furthermore, although the explained cumulative variance is relatively low (56.52\%), it suggests that artificial vibrotactile stimuli may not adequately emulate tactile sensations that are generated by genuine physical materials. However, this result proposes a new insight towards possible applications of artificial tactile stimuli in the future.

Future works will include expanding the model with possible addition of new onomatopoeias/adjectives, developing preliminary device prototype that utilized touch perception model in this research, and developing its corresponding user interface. Specifically, the future works will be aimed at developing comprehensive tactile mapping and symbol that can be used to convey message universally.

Acknowledgement. This work was supported by JSPS KAKENHI Grant Number 245436 .

\section{References}

1. Chen, X., Shao, F., Barnes, C., Childs, T., Henson, B.: Exploring relationships between touch perception and surface physical properties. International Journal of Design 3(2), 67-77 (2009)

2. Shirado, H., Maeno, T.: Modeling of Human Texture Perception for Tactile Displays and Sensors. In: The First Joint Eurohaptics Conference and Symposium on Haptic Interface for Virtual Environment and Teleoperator Systems, Pisa, Italy, pp. 629-630 (2005) 
3. Shirado, H., Konyo, M., Maeno, T.: Modeling of Tactile Texture Recognition Mechanism. Journal of the Japan Society of Mechanical Engineers 73(733), 2514-2521 (2007) (in Japanese)

4. Hollins, M., Faldowski, R., Rao, S., Young, F.: Perceptual dimensions of tactile surface texture: A multidimensional scaling analysis. Perception \& Psychophysics 54, 697-705 (1993)

5. Tiest, W.M.B., Kappers, A.M.L.: Analysis of haptic perception of materials by multidimensional scaling and physical measurements of roughness and compressibility. Acta Psychologica 121, 1-20 (2006)

6. Hayakawa, T., Matsui, S., Watanabe, J.: Classification method of tactile textures using onomatopoeias. Journal of The Virtual Reality Society of Japan 15(3), 487-490 (2010) (in Japanese)

7. Konyo, M., Yoshida, A., Tadokoro, S., Saiwaki, N.: A tactile synthesis method using multiple frequency vibrations for representing virtual touch. In: IEEE/RSJ Int. Conf. on Intelligent Robots and Systems, Alberta, Canada, pp. 1121-1127 (August 2005)

8. Bolanowski, S.J., Gescheider, G.A., Verillo, R.T., Checkosky, C.M.: Four channels mediate the mechanical aspects of touch. Journal of the Acoustical Society of America 84, 1680-1694 (1988)

9. Ono, M.: Giongo, Gitaigo 4500: Nihongo Onomatope Jiten (4500 Onomatopoeias and Sound-symbolic Words: Japanese Dictionary of Onomatopoeias). Shogakkan (2007) (in Japanese)

10. Kamermans, M.: http: / /www.nihongoresources.com/

11. R Development Core Team, R: A Language and Environment for Statistical Computing (2010) 